\title{
(Ence)nação teatral: A representação do feminino em The Countess Cathleen, de William Yeats
}

\section{Theatrical performance: The representation of the feminine in The Countess Cathleen, by William Yeats}

\author{
Adelaine LaGuardia* \\ Universidade Federal de São João del-Rei, \\ São João del-Rei, Minas Gerais, Brasil \\ Raimundo Expedito dos Santos Sousa* \\ Universidade Federal de Minas Gerais, \\ Belo Horizonte, Minas Gerais, Brasil
}

\begin{abstract}
Resumo: Este artigo examina as figurações do feminino em The Countess Cathleen, primeira peça que o escritor William Yeats escreveu para o Irish Literary Theatre, veio teatral do nacionalismo cultural irlandês. A peça foi produzida em um projeto de nação que, a fim de provar a virilidade dos homens nativos, subestimada pelo imperialismo britânico, instaurou um código de hipermasculinidade que demandava, em complemento, um código de hiperfeminilidade análogo. Atento às especificidades desse contexto de produção, o trabalho focaliza a construção da protagonista, a Condessa Cathleen, com ênfase na dicotomia entre erotismo e sacrifício. A análise permite considerar que Yeats se valeu de elementos da hagiografia como forma de heroificar a personagem como emblema da resignação feminina e, sobretudo, como modo de salientar a incompatibilidade entre o ethos sacrificial e o amor romântico.
\end{abstract}

Palavras-chave: Yeats. Teatro. Representação. Mulher. Hagiografia.

\begin{abstract}
This paper examines the female figuration in The Countess Catbleen, first piece the writer William Yeats wrote to the Irish Literary Theatre, the theatrical bias of Irish cultural nationalism. The play was produced in a national project that, in order to prove the virility of native men, underestimated by British imperialism, introduced a hypermasculinity code which required, in addition, an analogous hiperfemininity code. Attentive to the specificity of this production context, the paper focuses on the construction of the protagonist, Countess Cathleen, emphasizing the dichotomy between eroticism and sacrifice. The analysis let us consider that Yeats took advantage of hagiography elements as a way to heroficate the character as an emblem of female resignation, and especially as a way to emphasize the incompatibility between sacrificial ethos and romantic love.
\end{abstract}

Keywords: Yeats. Theater. Representation. Woman. Hagiography

\footnotetext{
* Professora da Universidade Federal de São João del-Rei. E-mail: adelaineufsj@gmail.com.

** Doutorando em Teoria da Literatura e Literatura Comparada na Faculdade de Letras da Universidade Federal de Minas Gerais._E-mail: raimundo_sousa@terra.com.br.
} 


\section{INTRODUÇÃO}

Em trabalho seminal, Anderson (1983) sublinha a instrumentalidade da imprensa na consolidação do nacionalismo moderno por facultar, mediante produção e circulação de textos em larga escala, a difusão do sentimento de integralidade entre concidadãos que se imaginam pertencentes a uma comunidade una e indivisa. Embora passe ao largo da universalização de valores dominantes, não problematizando, como aponta Chatterjee (1993), qual ideia de nação é imaginada a expensas de qual e quem a imagina em detrimento de quem, sua definição supera o reducionismo das precedentes ao caracterizar a nação, para além de entidade geopolítica, como um construto ficcional que, todavia, não se dá ex nibilo, mas mediante apropriação de repertórios culturais disponíveis. Se esse exercício imaginativo dependeu de gêneros textuais como o jornal impresso (ANDERSON, 1983) e o romance (SOMMER, 1991), os irlandeses, majoritariamente iletrados e despossuídos de tradição romanesca, dependeram de antigas práticas orais como a canção e a dramatização para se imaginarem, de maneira que a nação seria mais ouvida e contemplada do que propriamente lida, tal como sugere Yeats ao metaforizá-la como uma plateia assistindo à sua própria história dramatizada:

Uma nação deveria ser como uma plateia em um grande teatro [...] assisting ao drama de sua própria história $[\ldots]$ esse drama sagrado deve, para todos os olhos e ouvidos nativos, tornarse a maior de todas as parábolas (apud HETHMON JR, 1956, p. 17).

Uma vez que a nação, longe de imaginada de forma definitiva, depende de contínua reinvenção, o teatro a significaria iterativamente, de modo que a produção dramática, para além de entretenimento, assumiria a missão pedagógica de disseminar uma "consciência nacional". Dado que, paralelamente à luta anticolonial, conflitos intestinos levavam ao enfrentamento entre facções políticas antagônicas que pleiteavam a primazia de determinar como e por quem a nação seria imaginada, "o drama (produção de textos para encenação) e o teatro (formação dos meios de produção e condições de recepção do drama) seriam instrumentais na definição e sustentação de uma consciência nacional" (MURRAY, 1997, p. 3). Como "mídia" de maior envergadura do que o texto impresso, o teatro era ovacionado como instrumental no processo de descolonização, enquanto tribuna de expressão nacional(ista), por lideranças políticas como Arthur Griffith (1902), que apontou o Irish National Theatre como "um poderoso agente na construção de uma nação" (p. 2), e o Sinn Féinn, que o enalteceu como "a maior força nacionalizadora de que temos posse" (apud DEAN, 2010, p. 61). Tal seria o contributo do drama no processo de descolonização do imaginário que a Irlanda, primeira colônia inglesa a obter independência, inspiraria outras a também se valerem do drama em seus projetos de emancipação, tais como a Austrália, onde Louis Esson, à semelhança dos irlandeses, criou um teatro nacional; a Nigéria, onde escritores como Wole Soyinka se interessaram, a partir dos irlandeses, pela relação entre teatro e nacionalismo; e o Caribe, onde Derek Walcott se inspirou em Synge (INNES, 2007).

O teatro conquistou hegemonia cultural ao propalar a unidade na (a)d(i)versidade ou seja, a suplantação da antiga querela entre separatistas e unionistas e a então recente 
cisão do Partido Nacionalista após a queda de Parnell - negando qualquer filiação política, sob promessa de manter-se "fora de todas as questões políticas que nos dividem" (GREGORY, 1913, p. 9). Ao se comprometerem, ainda, em mostrar a um público "cansado de representações distorcidas" que a Irlanda "não é o templo da bufonaria e do sentimento gratuito, como tem sido representada, mas o templo de um idealismo ancestral" (op. cit., p. 9), os idealizadores do movimento teatral prometiam desconstruir estereótipos coloniais para um público ávido por exibições espe(ta)culares das virtudes nativas. Tal expectativa se fundava numa concepção teatral emergente ainda na Antiguidade, pois desde a Poética de Aristóteles se identifica o teatro, notadamente a tragédia, à noção de sacrifício por tematizar a inelutabilidade do destino em face do qual o sofrimento e imolação do herói purgam a audiência mediante identificação catártica cujo efeito terapêutico Freud (1969[1906]) comparou ao experienciado pela criança em brincadeiras de faz-de-conta. Do mesmo modo que esta reage à angústia decorrente de suas restrições e fragilidades imaginando-se capaz de lograr grandes feitos, o espectador, ao identificar-se com o herói, sente-se ele próprio um grande homem e, em fantasia, transporta-se de sua condição anódina para uma dimensão sobre-humana. A expectativa de cumprimento dessa função terapêutica pelo teatro seria determinante no circuito de produção e recepção das peças, pois, como demonstrarei nas análises que se seguem, a estética sacrificial da tragédia se orquestrou de tal sorte com a ética sacrificial do nacionalismo que a valoração do teatro teria como quesito primeiro a satisfação de uma plateia ávida por kathársis.

Essa especificidade teria implicações contundentes nas figurações de personagens do gênero feminino em um nacionalismo balizado por rígidas assimetrias de gênero. $\mathrm{A}$ fim de provar a virilidade dos homens nativos, subestimada pelo imperialismo britânico, o projeto de nação instaurou um código de hipermasculinidade que demandava, em complemento, um código de hiperfeminilidade análogo. Assim, a recursividade da mulher como provação/comprovação da virtude masculina denota uma particularidade do projeto nacional irlandês que o distingue, por exemplo, dos latinoamericanos, em cujas ficções fundacionais o romance atuava como dispositivo harmonizador enquanto "solução" para conflitos diversos na medida em que interpelava o leitor a se identificar com o par romântico, de forma que a suplantação dos obstáculos à concretização do romance estimularia um análogo enfrentamento dos percalços à consolidação da nação (SOMMER, 1991).

Em contraponto a Sommer, que cogita se no âmbito europeu o romance teria função similar, demonstrarei no restante deste capítulo que na politização do gênero e generização da política pelo nacionalismo irlandês nem o romance como gênero literário nem o romance como enlace amoroso foram priorizados. Para tanto, empreenderei análise de uma das peças mais emblemáticas do nacionalismo irlandês, The Countess Cathleen, de William Yeats, apresentada ao público em 1899, por ocasião da abertura do projeto nacionalista Renascimento Literário Irlandês (Irish Literary Renaissance). Ao focalizar a construção da protagonista, a Condessa Cathleen, que dá título à peça, argumentarei que o autor se valeu de elementos da hagiografia como forma de heroificar 
a personagem como emblema da resignação feminina e, sobretudo, como modo de salientar a incompatibilidade entre o ethos sacrificial e o amor romântico.

\section{CATHLEEN E A SCIENTIA AMORIS}

No debút oficial do movimento dramático, a encenação de The Countess Cathleen, em 8 de maio de 1899, foi tumultuada por um grupo de universitários católicos que protagonizaram, eles próprios, a cena primária de um Teatro Nacional não raro recebido com ambivalência por uma platéia sequiosa por confirmação de sua autoimagem. Todavia, quem mais contribuiu para a difamação da peça foi o parlamentar Frank Hugh O'Donnell (1899a, 1899b), que, em campanha na imprensa e nos círculos literários, conquistou aliados contra a peça que acusou de representar os irlandeses como "inviris" (unmanly) e afeitos a superstições "tal qual uma sórdida tribo de pretos, do Congo ou da Nigéria, que cultuam diabos e fetiches” (O’DONNELL, 1899a, p. 6). Sua denúncia, informada pela etnologia comparativa, sintetiza um conjunto de ansiedades identitárias que balizou a recepção da peça. Em face de um discurso colonial que ridicularizava os irlandeses como efeminados e seu catolicismo como ritualístico e fetichista, esperava-se que o teatro, coadunando-se com o esforço nacionalista, sublinhasse sua hombridade e espiritualidade em vez de sua efeminação e superstição. Yeats (1936), ao alegar ter-se esquecido, em sua experimentação estética, de que na Irlanda os símbolos "não são símbolos, mas realidades" (p. 36), ignorou que, como a nação já era imaginada a priori do movimento teatral, este deveria iterá-la performativamente, respeitando o "horizonte de expectativas" do público, e que, por haver um repertório de práticas de representação precedente ao teatro, alguns símbolos, como os camponeses, tinham significado cristalizado e, portanto, uma hermenêutica restritiva. Daí O’Donnell (1904), noutro texto, rotular suas peças como "paródias da Irlanda" (p. 30), pressupondo haver uma representação original que estas deturpavam.

$\mathrm{Na}$ peça em que os camponeses assolados pela miséria barganham sua alma com o demônio e são salvos por uma aristocrata que negocia sua própria alma para resgatar-lhes as suas, a recepção condenatória se devia ao fato de Yeats deslocá-los de sua posição totêmica para representá-los como afeitos a vícios os mais diversos. Devia-se, ainda, à sua exegese inconsistente, na qual uma mulher vende a alma ao diabo e, ainda assim, é santificada sob a justificativa de que "[a] luz das luzes olha sempre para o motivo, não para o feito" (YEATS, 1912 1 , p. 111). Para nacionalistas a braços com o estigma de paganismo, sua teologia pautada no princípio de que os fins justificam os meios não passava de uma "filosofia pagã" (O’DONOGHUE, 1919, p. 29).

Embora situada cronologicamente em um passado longínquo, a peça remonta ao contexto da Grande Fome, quando, em face da miséria que se abatia sobre os camponeses católicos, a aristocracia protestante teria ignorado sua penúria ou, no máximo, matadolhes a fome desde que se convertessem ao seu credo (FRAZIER, 1990). Nessa contextualização socioeconômica pouco observada pela crítica reside, a nosso ver, a chave

${ }^{1}$ Doravamente o texto será referenciado pela abreviação $C C$ seguida do número da página. 
para se compreender a disjunção entre os propósitos da peça e sua recepção, já que Yeats propõe um nacionalismo conciliatório, adverso ao sectarismo social, que, no entanto, resulta contraproducente por acentuar a desigualdade subjacente ao sacrifício da nobreza em prol do campesinato. Frank Hugh O’Donnell (1904), ao questionar a representação do demônio como "um perito de marca superior que não se importa em dar 500.000 coroas por uma alma da superior aristocracia" (p. 28), observou que o contraste entre a disposição dos demônios em pagar uma fortuna pela alma de Cathleen e sua má vontade em oferecer uma ninharia pela alma dos camponeses acena uma hierarquia moral que, em última instância, alude à hierarquia de classes. Ainda que a peça alegorize, como sustenta Cullingford (1981), a benevolência da aristocrata Maud Gonne para com o campesinato, a condescendência dos camponeses quanto à superioridade de uma aristocrata era intolerável, sobretudo pela vinculação da classe dominante ao protestantismo e, por extensão, ao império. Na contramão de uma ordem social mais flexível que se desenhava sob impacto dos Land Acts, Yeats idealiza uma dinâmica de classe em que ricos e pobres devem permanecer como tais. Ao informar à condessa, com ufanismo, que "meus ancestrais serviram aos seus, madame, há mais tempo do que podem os livros contar $(C C$, 17), a camponesa Mary sugere uma natural hierarquia de classes cuja origem se perde na aurora dos tempos. Eis porque os nacionalistas repudiaram a harmonia com que Yeats representava a relação entre as classes e, mais ainda, a sua idealização da aristocracia como natural protetora do campesinato: se, de um lado, o nacionalismo inclusivo respondia ao anseio do escritor angloirlandês em obliterar a esquizofrenia cultural decorrente de sua identidade hifenizada, por outro, em análise material, consistia em um elogio da estratificação e imobilidade social. Se bem que, em rejeição ao materialismo pequenoburguês, Yeats preconizasse a aliança entre camponeses e aristocratas pelo fato de ambos priorizarem o capital cultural sobre o econômico, seu romance com a Casa Grande o levava a priorizar qualitativamente valores e convenções aristocráticos. Daí Maud Gonne, aristocrata mas não aristocrática, refugar a peça escrita em sua homenagem por considerar opressiva a relação de classes estabelecida por Yeats.

A leitura de The Countess Cathleen revela que Yeats, embora refugado pela audiência, desenvolveu uma teologia para justificar o sacrifício da condessa, construindo a peça como um texto sagrado e sua protagonista como uma santa. Ao subintitulá-la "A Miracle Play", o autor retoma não apenas um gênero dramático medieval como, a nosso ver, outro gênero textual típico do período, a hagiografia. Adotando um recurso que se tornaria lugar-comum no nacionalismo, o escritor se apropria transculturalmente da teologia católica para condensar em Cathleen valores tanto mariais quanto cristológicos. Atuando como "mãe" dos camponeses, Cathleen alude à Virgem Maria; sacrificando-se por eles, alude a Jesus Cristo, identificação que a aproxima, por tabela, das celibatárias medievais, já que, para a ética cristã, propulsora do sadomasoquismo ocidental, salvam-se apenas os que padecem à maneira de Cristo.

Embora Yeats proviesse de família protestante, possivelmente a construção dessa personagem foi impactada pelo catolicismo, que na segunda metade do século XIX se tornara ainda mais intenso no país. O culto à Virgem, desenvolvido tardiamente no catolicismo e tratado com reservas pelo magistério de uma Igreja androcêntrica para não 
eclipsar a trindade masculinizada nem reavivar o culto pagão às deusas da fertilidade (cf. BOFF, 1979), foi revigorado no século XIX com o recrudescimento do marianismo nos países católicos, haja vista que apenas em 1854 foi instituído o Dogma da Imaculada Conceição, por Pio IX, que culminaria, em 1950, no Dogma da Assunção, por Pio XII (SANT'ANNA, 1985). Na Irlanda, país que experienciou uma revolução devocional particular em meados do Oitocentos sob os auspícios do catolicismo ultramontano (cf. LARKIN, 1972), a Igreja, em face da miséria instalada após a Grande Fome, ergueu a Virgem como alento espiritual para os sobreviventes, que a adotaram como uma Mãe que os guardaria sob seu manto protetor, e como exemplo de castidade para viúvas e solteironas (INNES, 1993). Investida de um conjunto de atributos cristalizados no imaginário ocidental cristão, Maria fornecia um perfil identitário pronto, que bastaria ser associado às irlandesas como se lhes fosse peculiar. Desse modo, ideólogos nacionalistas vangloriavam-se superlativamente da mulher irlandesa como "o tipo mais excelso do mundo em feminilidade e virgindade" (SPARLING, 1913, p. 45), que possivelmente ganharia "o primeiro prêmio do mundo em modéstia e pureza virginal" (CASSIDY, 1922, p. 206).

Entregue a um beatismo masoquista, contrastante com o hedonismo do poeta Aleel, que, enamorado, tenta dissuadi-la da obsessão messiânica, Cathleen antepõe ao amor carnal sua missão redentora, interditando sua investidura ao lhe pedir que "[n]ão me estenda suas mãos suplicantes”, pois “[e]ste coração jamais despertará na Terra” $(C C, 58)$. Empenhada em orar até que seu coração "[t]enha alcançado os Céus como uma árvore, e lá / Farfalhado suas folhas até que os Céus salvem meu povo" $(C C, 59)$, a condessa, ao modo das santas medievais, pressupõe a purificação espiritual como quesito para a compaixão divina, numa relação causal que torna inadmissível o abandono às paixões. Sua busca por elevação espiritual é simbolizada pelo desejo de que o coração, pólo do seu corpo, alcance os Céus - desejo que, todavia, revela um gradiente erótico, já que, segundo Bataille (1957), a busca mística de ligação com a divindade também remete à função unificadora de Eros.

Numa díade agostiniana entre caritas e cupiditas, Cathleen remonta ao paradigma de santidade presente em hagiografias cujo enredo não raro tematiza o esforço de celibatárias resistentes a assédios, ameaças e agressões para preservar a virgindade, prova de lealdade a Deus - vejam-se os casos paradigmáticos de Santa Agnes, que teria resistido às pressões de um pretendente pagão, sob pena de ameaças e torturas, e Santa Cecília, que, obrigada a se casar, teria persuadido o marido à castidade (ELLIOT'T, 1993). No esforço de Cathleen pela domesticação sensorial, a peça encerra uma economia libidinal de desejo e interdição que culmina com um veto categórico à realização amorosa, na medida em que a heroína se defronta com injunções inconciliáveis e se vê obrigada a decidir-se entre uma e outra. Ao se definir como "o cântaro vazio" $(C C, 59)$, a condessa credita a recusa ao amor de Aleel ao seu esvaziamento e exaustão devido à canalização libidinal para a missão redentora. Contudo, ao lhe pedir que vá embora sem olhar para trás, pois, "[a] cima de tudo, eu não suportaria seu olhar" (CC, 60), sugere que a continência, enquanto autoflagelação, configura um sacrifício também para ela; afinal, a renúncia aí decorre não da ausência de desejo, mas do contato com este e constatação de sua inexequibilidade. 
Nessa perspectiva, Cathleen foge ao padrão hagiográfico ao lutar contra o desejo residente em si mesma, e tal diferença confere ambiguidade à posição de Yeats quanto à ética sacrificial. Escrita sob impacto da rejeição de Maud Gonne à sua proposta de casamento para se dedicar à militância nacionalista, a peça alude à ambivalência do escritor entre admiração e indignação pelo altruísmo desmedido.

Partidário da revolta contra o racionalismo ${ }^{2}$, Yeats contrapõe, na figura de Cathleen, a razão e o sentimento, inscrevendo o amor como única ciência digna e a peça como um exemplo de Scientia Amoris $^{3}$. O escritor, a fim de demonstrar como a Irlanda era "romântica e espiritual em vez de científica e analítica" (apud MARCUS, 1987, p. 21), faz de Cathleen um símbolo dessa revolta, mas, ao fazê-lo, endossa a clivagem ocidental entre logos/homem e pathos/mulher na medida em que o mérito da heroína que se deixa ludibriar pelos demônios e vende sua alma precipitadamente reside menos na inteligência do que na ânsia de servir. A convencionalidade de Yeats se evidencia, portanto, na formatação do sacrifício de Cathleen, cujo signo não é o corpo, mas a alma, metonímia da mulher numa cultura ocidental que associa o feminino a valores abstratos. Mais: embora o salvamento dos camponeses consagre seu heró́smo, a condessa é resgatada por anjos masculinizados que disputam sua alma com diabos em arquetípica contenda entre o Bem e o Mal, de modo que, embora a analogia da condessa com Jesus Cristo seja sobredeterminante, sua agência limitada a aproxima da Virgem, pois depende de intermediação para ascender aos Céus.

À diferença da maioria dos oponentes a The Countess Cathleen, detidos a críticas de ordem moral, Ernest Boyd (1916) atentou para a inexpressividade da cena que, em princípio, seria o clímax da peça ao afirmar que embora o "tema do sacrifício" seja inerente ao drama, Yeats foi incapaz de explorá-lo e, consequentemente, numa peça de tensão vaga e ação difusa "o momento supremo do sacrifício de Kathleen passa quase despercebido" (p. 146). O jornalista não observou, porém, que a falha em exprimir a "intensidade dramática" do ato sacrificial decorria não tanto da inconsistência textual, mas como de certo comedimento na exposição de um sacrifício feminino desafinado com a retórica nacionalista que relegava a mulher à condição de objeto de contenda e ovacionava o sacrifício másculo. De fato, ao atribuir a uma só personagem duas funções - a metáfora e a metonímia - em cuja cisão os papéis de gênero eram formatados no projeto nacional, Yeats se enredou numa teia de inconsistências concorrentes para o insucesso da peça. Ainda que se apercebesse das deficiências estruturais do texto, revisando-o diversas vezes, o autor não considerou sua inconsistência simbólica. Em consequência da articulação, numa única personagem, de papéis duais como mãe e namorada, símbolo e agente, heróina e vítima, resultaram abortivas suas pretensões de agradar Maud Gonne e de propor um nacionalismo conciliatório. Ao sugerir metonimicamente, com os camponeses,

\footnotetext{
${ }^{2}$ Movimento multidisciplinar que, em resistência ao cientificismo, sobretudo a doutrina positivista, propugnava a subjetividade em detrimento da racionalidade. Animado por reações como o Concílio Vaticano I (na Igreja católica), os movimentos pietistas (no protestantismo), o espiritualismo (em correntes como o esoterismo e a teosofia) e o espiritismo de Allan Kardec, tal movimento animou o pensamento social europeu entre 1890 e 1930 (cf. HUGHES, 1958).

${ }^{3}$ Remetemo-nos à condecoração "perita na Scientia Amoris", conferida por João Paulo II (2001) a Thérèse de Lisieux ao nomeá-la Doutora da Igreja.
} 
um povo inobediente aos preceitos cristãos e despossuído de valores morais; ao sugerir, metaforicamente, uma nação destrutível e inapta à autogestão; e ao alegorizar a Irlanda como uma mãe simbólica que, apesar de seu instinto maternal, não provém da mesma classe social que os filhos, Yeats fracassou em sua primeira exploração da figura feminina como alegoria da nação.

\section{CONSIDERAÇÕES FINAIS}

A construção da personagem Cathleen remonta à clivagem entre alma e corpo, espiritualidade e carnalidade, que na ideologia cristã caracteriza o ser humano cindido entre campos de força do Bem e do Mal. Nesse sentido, essa figuração feminina parecenos forjada com base nos protótipos de Jesus Cristo e, sobretudo, da Virgem Maria. Essa última analogia implica um impasse para a personagem, assim como para as irlandesas à época. Dado que apenas a Virgem, a única de seu sexo, foi poupada do estigma partilhado por todas as mulheres (cf. WARNER, 1976), concebê-la como protótipo de feminilidade para a mulher irlandesa implicava impor a esta última um padrão comportamental inexequível, já que era impossível preencher conjuntamente dois quesitos de feminilidade inconciliáveis, a virgindade e a maternidade.

The Countess Cathleen evidencia esse paradoxo na medida em a personagem homônima se vê a braços com o dilema entre o amor romântico e o sacrifício ascético e se volta para o último. Assim, a peça sugere uma diferença estrutural entre o projeto nacional irlandês e os latinoamericanos estudados por Sommer (1991) no tocante à erotização da política e à politização do erotismo. Enquanto, na análise de Sommer, o objetivo erótico opera como expressão microscópica do sentimento de nação, resultando que "as frustrações eróticas são desafios ao desenvolvimento nacional" (p. 50), nas ficções de fundação irlandesas o desmantelamento do romance é crucial para a arquitetura da nação, impelindo o público a exaltar o malogro do par romântico como um necessário sacrifício patriótico.

\section{REFERÊNCIAS}

ANDERSON, Benedict. Imagined Communities: Reflections on the Origin and Spread of Nationalism. London: Verso, 1983.

BATAILLE, Georges. L'érotisme. Paris: Minuit, 1957.

BOFF, Leonardo. O rosto materno de Deus: ensaio interdisciplinar sobre o feminismo e suas formas religiosas. Rio de Janeiro: Vozes, 1979.

BOYD, Ernest. Ireland's Literary Renaissance. Dublin, London: Maunsel \& Co., 1916.

CASSIDY, James F. The Women of the Gael. Boston: The Stratford Company Publishers, 1922. 
CHATTERJEE, Partha. Whose Imagined Community. In: CHATTERJEE, Partha. The Nation and its Fragments: Colonial and Postcolonial Histories. Princeton: Princeton University Press, 1993, p. 3-13.

CULLINGFORD, Elizabeth B. Yeats, Ireland, and Fascism. New York: New York University Press, 1981.

DEAN, Joan F. Riot and Great Anger: Stage Censorship in Twentieth Century Ireland. Madison: University of Wisconsin Press, 2010.

ELLIOTT, Dyan. Spiritual Marriage: Sexual Abstinence in Medieval Wedlock. Princeton: Princeton university press, 1993.

FRAZIER, Adrian. Bebind the Scenes: Yeats, Horniman, and the Struggle for the Abbey Theatre. Berkeley, Los Angeles: University of California Press, 1990.

FREUD, Sigmund (1906). Tipos Psicopáticos no Palco. Edição Standard Brasileira das Obras Psicológicas Completas de Sigmund Freud. v. VII. Rio de Janeiro. Imago, 1969.

GREGORY, Lady Augusta. Our Irish Theatre: A Chapter of Autobiography. New York: G. P. Putnam's Sons, 1913.

GRIFFITH, Arthur. Editorial. United Irishman, 8 de novembro de 1902, p. 1.

HETHMON JR, Robert Henry. The theatre's anti-self: a study of the symbolism of Yeats' unpopular plays. Stanford, 1956. Tese (Doutorado). Dept. of Speech and Drama, Stanford University, Stanford, 1956.

HUGHES, H. Stuart. Consciousness and Society: The Reorientation of European Social Thought, 1890-1930. New York: Alfred A. Knopf, 1958.

INNES, Catherine L. The Cambridge Introduction to Postcolonial Literatures in English. Cambridge: Cambridge University Press, 2007.

INNES, Catherine L. Woman and Nation in Irish Literature and Society, 1880-1935. Athens: University of Georgia Press, 1993.

JOÃO PAULO II. Apostolic Letter Novo Millennio Ineunte of His Holiness Pope John Paul II to the Bishops Clergy and Lay Faithful at the Close of the Great Jubilee of the Year 2000. Vaticano, 6 de janeiro de 2001. Disponível em: < http://www.doxaweb.com/assets/novo.pdf> Acesso: 25 mar. 2017. 
LARKIN, Emmet. The Devotional Revolution in Ireland, 1850-75. American Historical Review, v. 77, n. 3, p. 625-652, 1972.

MARCUS, Phillip L. Yeats and the Beginning of the Irish Renaissance. Syracuse, New York: Syracuse University Press, 1987.

MURRAY, Christopher. Twentieth-Century Irish Drama: Mirror Up to Nation. Manchester: Manchester University Press, 1997.

O’DONNELL, Frank Hugh. Celtic Drama in Dublin. Freeman's Journal, I, 1899a, p. 6.

O’DONNELL, Frank Hugh. Souls for Gold: A Pseudo-Celtic Drama in Dublin. London: Nassau Press, 1899b.

O'DONNELL, Frank Hugh. The Stage Irishman of the Pseudo-Celtic Drama. London: John Long, 1904.

O’DONOGHUE, M. J. Men and Movements. Winona: St. Mary’s Training School, 1919.

SANT'ANNA, Affonso Romano de. O canibalismo amoroso: o desejo e a interdição em nossa cultura através da poesia. São Paulo: Brasiliense, 1985.

SPARLING, C. John. The Irish-Canuck-Yankee. Chicago: M. A. Donohue \& Company, 1913.

SOMMER, Doris. Foundational Fictions: The National Romances of Latin America. Berkeley, Los Angeles, Oxford: University of California Press, 1991.

YEATS, William Butler. Dramatis personae, 1896-1902: Estrangement, The Death of Synge, The Bounty of Sweden. London: The Macmillan Company, 1936.

YEATS, William Butler (1899). The Countess Cathleen. In: Poems. London: T. Fisher Unwin, 1912, p. 1-111.

WARNER, Marina. Alone of All Her Sex: The Myth and the Cult of the Virgin Mary. London: Picador, 1976.

Recebido em: 23/03/2017 